\title{
MODEL DAN EFEK DUKUNGAN SOSIAL TERHADAP KEPATUHAN PENGOBATAN PASIEN TUBERKULOSIS RESISTEN OBAT : A LITERATURE REVIEW
}

\author{
Sudirman Efendi ${ }^{1}$, Elly Lilianty Sjattar ${ }^{2}$, Yuliana Syam ${ }^{3}$ \\ Email : sudirdg.ngalli@gmail.com \\ ${ }^{1}$ Postgraduate Student in Nursing, Faculty of Nursing, Hasanuddin University, Makassar, Indonesia \\ 2,3 Department of Medical Surgical Nursing, Faculty of Nursing, Hasanuddin University, Makassar, Indonesia
}

\begin{abstract}
Introduction: Tuberculosis is an infectious disease that often ends in death. Poor adherence is a major threat to control and encourages the emergence of drugresistant TB. Drug-resistant TB patients are synonymous with psychosocial problems such as stigma and psychological distress that impact adherence and treatment outcomes. Social support is the key to treatment adherence which includes emotional, informational, economic support and patient assistance during treatment. Purpose: This study aims to identify and describe the model and effect of social support on treatment adherence in drug-resistant TB patients.Methods: $P$ A literature review search was performed using the PICO keyword in four article databases, namely PubMed, Science Direct, ProQuest Cochrane Library and Gray literature. reported in English over the past six years on social support and drugresistant TB. Results: Based on the 6 articles reviewed, several were identified models or forms of social support interventions given to TB-resistant patients and has a positive impact on medication adherence. In addition, it also has an impact on increasing knowledge, reducing stigma and psychological problems which helps the patient's healing process.Conclusion: Social support has a positive impact on treatment adherence so it is recommended to be applied in treatment programs for drug-resistant TB patients.
\end{abstract}

\section{ABSTRAK}

Pendahuluan:Tuberkulosis merupakan penyakit menular yang sering berakhir dengan kematian. Kepatuhan yang buruk merupakan ancaman utama untuk mengendalikan dan mendorong munculnya TB yang resistan terhadap obat. Pasien TB yang resistan terhadap obat identik dengan masalah psikososial seperti stigma dan tekanan psikologis yang berdampak pada kepatuhan dan hasil pengobatan. Dukungan sosial merupakan kunci kepatuhan pengobatan yang meliputi dukungan emosional, informasional, ekonomi dan bantuan pasien selama pengobatan. Tujuan: Penelitian ini bertujuan untuk mengidentifikasi dan mendeskripsikan model dan pengaruh dukungan sosial terhadap kepatuhan pengobatan pada pasien TB resistan obat. Metode: Penelusuran literature review PA dilakukan dengan menggunakan kata kunci PICO pada empat database artikel yaitu PubMed, Science Direct, ProQuest Perpustakaan Cochrane dan literatur Gray. dilaporkan dalam bahasa Inggris selama enam tahun terakhir tentang dukungan sosial dan TB yang resistan terhadap obat. Hasil: Berdasarkan 6 artikel yang direview, teridentifikasi beberapa model atau bentuk intervensi dukungan sosial yang diberikan kepada pasien resisten TB dan berdampak positif terhadap kepatuhan minum obat. Selain itu juga berdampak pada peningkatan pengetahuan, pengurangan stigma dan masalah psikologis yang membantu proses penyembuhan pasien.Kesimpulan: Dukungan sosial berdampak positif terhadap kepatuhan pengobatan sehingga direkomendasikan untuk diterapkan dalam program pengobatan TB resistan obat pasien.

\section{ARTICLE INFO}

Keywords:

Dru resisten tuberculosis; Social support;

Treatment obedience

\section{Pendahuluan}

Global tubercolosis report ditahun 2018 memperkirakan 10 juta orang jatuh sakit dengan tuberculosis yang tersebar diseluruh dunia. Sekitar 5,7 juta pria, 3,2 juta wanita dan 1,1 juta pada anak-anak. Beberapa Negara menjadi sorotan atas prevalensi penyakit menular tersebut, dimana India memimpin di urutan pertama di ikuti oleh Cina dan juga Indonesia(1). Berdasarkan data Riskesdas tahun 2018, Notifikasi insidensi tuberkulosis di Indonesia naik menjadi 70\% dengan estimasi kasus TB sekitar 845.000 (2). Angka keberhasilan Pengobatan tuberkulosis masih belum optimal, oleh karena tingginya angka putus berobat yang dapat menyebabkan resistensi obat dan kegagalan pengobatan . Kepatuhan pengobatan TB sangat penting dalam mencegah kekambuhan dan munculnya Resistensi obat (3). TB-resisten obat 
tetap menjadi ancaman keamanan kesehatan, di Indonesia sendiri untuk kasus TB-MDR/RR ternotifikasi sebanyak 9,875 kasus ditahun 2018 (4).

Perawatan kasus TB sangatlah kompleks mulai dari persoalan pengetahuan yang kurang, stigma sosial, dukungan social dan masa pengobatan yang lama (5).(6). Stigma yang dirasakan diantara pasien di identifikasi sebagai factor utama ketidakpatuhan terhadap terapi DOTS (7)'(8). TBResisten obat masih menghadapi banyak tantangan psikososial seperti stigma dan tekanan psikologis yang menyebabkan kepatuhan dan hasil pengobatan yang buruk $(9,10)$. DOTS adalah strategi untuk meningkatkan kepatuhan pengobatan dengan mengawasi penggunaan obat pasien TB (11).

Intervensi sosial dan psikologis yang memerangi stigmatisasi dan depresi pada pasien TB harus diadopsi dan dioptimalkan untuk meningkatkan kepatuhan pengobatan (12). Factor psikososial memiliki pengaruh negatif pada kepatuhan program pengobatan TB, anggota keluarga mereka sebagai sosok yang paling mendukung secara sosial (13). DOTS juga diakui sebagai jenis dukungan sosial khusus (14). Petugas kesehatan bertanggung jawab untuk mengingatkan pasien dan keluarganya tentang janji temu berikutnya yang dijadwalkan pada saat pengambilan obat . Komitmen dan kualitas perawat yang memberikan dukungan sosial adalah elemen penting dari program ini (15). Sebagian besar pasien dan penyedia layanan terkait mengatakan bahwa dukungan sosial adalah faktor kunci untuk kepatuhan pengobatan TB-MDR, (16),(17). Hal diatas sesuai dengan pedoman WHO yang memuat dukungan social seperti dukungan informasi ,dukungan emosional, dukungan pendampingan dan dukungan material (18). Kekurangan dukungan sosial untuk pasien TB telah dilaporkan sebagai penghalang untuk pengobatan yang efektif (19).

Berbagai penelitian telah mengkaji efek dukungan sosial pada kepatuhan pengobatan pasien tuberkulosis(20), (9), (21). Namun tidak membahas berbagai model dukungan sosial dan efeknya pada kepatuhan menjalani program pengobatan pasien TB-Resisten obat. Oleh karena itu, penelitian ini diulas dengan kajian sistematik literatur yang bertujuan untuk mengidentifikasi serta mendeskripsikan model dan efek dukungan sosial pada kepatuhan pengobatan pasien TB-Resisten obat, yang akan bermanfaat terhadap pelayanan program Pengobatan TB.

Metode

Penelitian ini merupakan tinjauan literature review yang mengacu pada pedoman PRISMA guideline checklist dalam penulisan laporan (22), yang dapat di akses di http://prismastatement.org/PRISMAStatement/Checklist.aspx.. Kami menggunakan pedoman Critical Appraisal Skills Programme Tools (23).

untuk menganalisis kualitas pelaporan diantara study yang dipilih.

\section{Strategi pencarian dan peninjauan literature}

Pencarian literatur di gunakan untuk mengidentifikasi berbagai model intervensi dukungan social dan manfaatnya terhadap kepatuhan pasien TB-resisten obat dalam menjalani program pengobatan. Database yang digunakan adalah PubMed, Science Direct, Proquest, Cochrane Library dan Gray literature dengan batasan artikel yang diterbitkan antara tahun 2014 sampai 2020. Formulasi pertanyaan didasarkan pada PICO ( P: Penderita TB-resisten obat, I: Dukungan Sosial, C: - , O: Kepatuhan Pengobatan) . Kami juga secara manual memeriksa daftar referensi dari ulasan yang relevan dan termasuk mengambil tambahan studi yang berpotensi berkualitas.

\section{Pemilihan studi}

Pemilihan studi menggunakan pendekatan diagram PRISMA untuk literature. Proses pemilihan studi di ulas pada (Gambar 1), dan artikel yang dipilih berdasarkan kriteria 
inklusi yang ditetapkan yakni Populasi merupakan penderita TB-Resisten obat, Intervensi yang diberikan adalah dukungan social, Hasil penelitian berupa kepatuhan atau keberhasilan pengobatan ,Studi dilakukan dalam rentang waktu 6 tahun terakhir (2014-2020) dan Studi ditulis dalam bahasa Inggris dari berbagai negara. Sementara Studi akan dikecualikan jika populasinya adalah TB anak, artikel tidak ada full teks dan tidak relevan dengan penelitian.

\section{Analisis data}

Penulis bersama dua orang pembimbing menganalisa literature review dengan berfokus pada ulasan model dan manfaat dukungan sosial terhadap kepatuhan pengobatan pasien TB-Resisten obat. Penjelasan model dukungan sosial, durasi , pengukuran output dan hasil studi disajikan pada sintesis grid (Tabel 1).

Hasil

\section{Hasil pencarian studi}

Hasil skrining dari 5 database yang digunakan, pencarian artikel sebanyak 2.260. Hasil ekslusi publikasi 6 tahun terakhir $(n=746)$, bukan berbahasa inggris $(n=17)$. Judul dan abstrak tidak sesuai pertanyaan penelitian didapatkan $(n=1271)$ sehingga diperoleh 226 artikel. Kemudian hasil ekslusi yang tidak ada full text $(n=57)$, bukan eksperimen $(n=122)$ dan artikel duplikat $(n=13)$, tidak sesuai ouput penelitian $(n=28)$ Sehingga di dapatkan 6 artikel yakni 3 studi RCT, 1 studi Quasy eksperimen dan dua studi kohor sebagai referensi utama yang memenuhi kriteria ketat dari berbgai Negara seperti india, Cina, Indonesia, Afrika dan Armenia. Selanjutnya dapat dilihat pada (Gambar 1). 
Model dan Efek Dukungan Sosial terhadap Kepatuhan Pengobatan Pasien Tuberkulosis Resisten Obat : A Literature Review

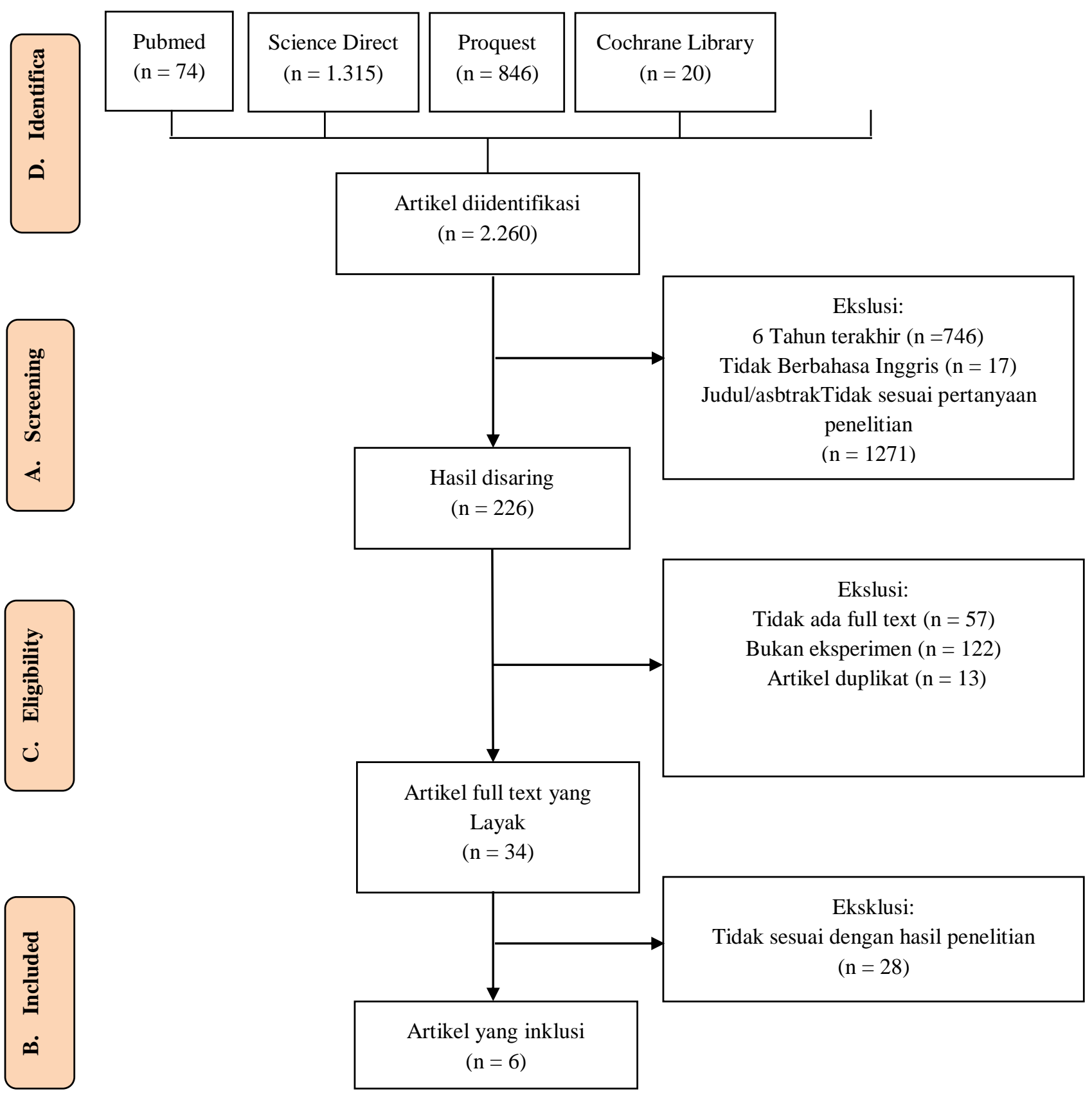

Gambar 1. Diagram Prisma

Gray literaure $(n=5)$ 
Intervensi dukungan social yang diberikan pada setiap studi berbeda-beda model dukungannya dengan hasil yang berbeda pula. Berikut ulasan berdasarkan model atau bentuk dukungan social yang diberikan tiap studi.

\section{Dukungan infomasi}

Terdapat tiga studi yang intervensinya memberikan bentuk dukungan social berupa dukungan informasi. Penelitian yang dilakukan oleh (24) dukungan informasi berupa Pendidikan kesehatan yakni dengan mengingatkan pasien untuk memperbaharui dan mematuhi pengobatan serta metode mengatasi kejadian buruk yang diberikan sekali dalam sebulan. Penelitian lainnya memberikan dukungan informasi berupa edukasi terkait penyakit TB dan pengobatannya serta konseling psikologis melalui pemberdayaan keluarga dengan durasi konseling rat-rata 120 menit selama 5 bulan (25). Selain itu, studi lain memberikan dukungan edukasi berbasis Health belief model (HBM) selama 4 bulan, dibulan pertama dilakukan sekali seminggu, dan selanjutnya sekali sebulan hingga 7 sesi (26).

\section{Dukungan materi}

Untuk dukungan social dalam bentuk materi, di identifikasi dua studi yang memberikan dukungan tersebut yakni penelitian oleh (27) memberikan dukungan sosial ekonomi dalam bentuk pemberian uang tunai untuk keperluan penyediaan suplemen gizi seperti susu, telur, biji-bijian dan lainnya. Sementara penelitian lain memberikan dukungan finansial berupa Penggantian biaya transportasi sebesar US \$ 10 dan dukungan nutrisi sebesar US \$ 10 (24). Masing -masing studi memberikan dukungan materi sekali dalam sebulan.

\section{Dukungan persahabatan}

Terdapat tiga studi yang intervensinya memberikan bentuk dukungan social berupa dukungan persahabatan. Seperti penelitian oleh (25) yang memberdayakan keluarga pasien sebagai pendukung dalam mendapatkan edukasi terkait penyakit dan pengobatannya selama 5 bulan. Beberapa Penelitian memberikan dukungan ini dengan memfasilitasi pertemuan kelompok antar penderita TB-resisten obat dengan berbagi pengalaman bersama selama pengobatan(27,28). Pada penelitian (28) dukungan Peer Group dilakukan dalam 4 tahap selama 4 minggu dengan durasi 45-60 menit, sementara pada penelitian (27) tidak dijelaskan secara detail mengenai durasi yang digunakan.

\section{Dukungan emosional}

Dari 6 artikel yang diulas, semua studi yang dilakukan terdapat intervensi dukungan emosional yang diberikan kepada pasien TB-resisten obat. Bentuk dukungannyapun cukup variatif seperti pada penelitian oleh (24) dukungan berupa pengawasan pengobatan yang diberikan tiap hari melalui program DOTS. Kunjungan mingguan di klinik oleh petugas kesehatan terlatih serta mamantau kepatuhan pengobatannya melalui telepon dan sms (25). Penelitian lain memberikan dukungan berupa rehabilitasi hingga selesai pengobatan, dukungan nutrisi dan juga layanan program RNCTP. Selain itu, kelompok intervensi juga dikunjungi oleh tim kesehatan di rumah pasien(29). Pada penelitian oleh (26), dukungan emosional berupa konseling psikologis oleh petugas kesehatan yang bertujuan untuk mengurangi tekanan psikologis pasien selama menjaani pengobatan. Dukungan psikoemosional dalam bentuk motivasi dan kunjungan rumah pasien (27), sementara pada peneltian yang dilakukan oleh (28) dukungan emosional diberikan dengan difasilitasi pertemuan kelompok antar sesama penderita TB-resisten yang bertujuan saling memberikan support dengan berbagi pengalaman masing-masing.

Dari berbagai model intervensi dukungan social yang diberikan , masing-masing memiliki hasil yang positif pada kepatuhan pengobatan pasien. Penelitian oleh (24) menunjukkan bahwa dukungan sosia terbukti meningkatkan kepatuhan serta dapat memprediksi keberhasilan pengobatan. Penelitian oleh (25) mengungkapkan bahwa setelah diberikan dukungan berupa 
konseling dan edukasi berbasis keluarga, kunjungan di klinik, serta memantau pengobatannya melalui telepon/sms, kepatuhan serta keberhasilan pengobatan menjadi meningkat. Selain itu, pengetahuan juga meningkat, dan menekan depresi serta stigma penderita TB-resisten. Pada penelitian (28) dengan intervensi dukungan peer group support terbukti meningkatkan kepatuhan pengobatan dan juga efikasi diri . Begitupun penelitian oleh (29) dengan dukungan konseling serta kunjungan rumah oleh petugas kesehatan, dukungan nutrisi dan layanan RNCTP juga terbukti meningkatkan kepatuhan, menekan stigma serta penolakan dan juga meningkatkan kesembuhan pasien. Sementara pada penelitian (26) setelah diberikan dukungan social berupa konseling psikososial dan edukasi berbasis HBM juga terbukti menekan ketidakpatuhan pengobatan dan mengurangi tekanan psikologis serta meningkatkan pengetahuan pasien terkait TB. Penelitian lainnya oleh (27) juga berhasil menekan ketidakpatuhan dan meningkatkan keberhasilan pengobatan setelah diberikan dukungan social berupa konseling, uang tunai serta dukungan nutrisi

\section{Diskusi}

Terdapat enam artikel yang diulas dalam tinjauan literature ini untuk mengetahui apa saja model atau bentuk dukungan sosial serta efeknya terhadap kepatuhan pengobatan pada pasien TB-resisten obat. Di identifikasi berbagai bentuk dukungan sosial yang diberikan, namu tujuan dari tiap intervensi tetap berfokus pada kepatuhan pasien dalam menjalani pengobatan baik sebagai ouput primer maupun output sekunder.

\section{Model dukungan social}

Bentuk dukungan sosial yang diberikan pada 6 studi yang direview terdiri dari dukungan informasi, dukungan materi, dukungan pendampingan dan dukungan emosional. Hal tersebut searah dengan pedoman penanggulangan TB-resisten obat yang memuat ke empat sumber dukungan tersebut (18). Namun tidak semua intervensi studi yang diberikan mencakup keempat aspek dukungan social tersebut, terdapat dua studi $(24,27)$ yang memberikan dukungan social secara komprehensif . Bentuk dukungan finansial berupa Penggantian biaya transportasi dan kebutuhan nutrisi, bentuk dukungan informasi berupa intervensi edukasi dan konseling kesehatan pada pasien, dukungan pendampingan yakni dengan menfasilitasi para penderita untuk saling berbagi pengalaman pengobatan antar pasien TB-resisten obat, sementara dukungan emosional diberikan dalam bentuk motivasi dan kunjungan rumah dan juga pengawasan minum obat melalui layanan DOT. Hal tersebut didukung oleh penelitian yang mengungkapkan bahwa dukungan sosial yang komprehensif termasuk pendidikan kesehatan, psikoterapi dan intervensi dukungan keluarga atau masyarakat, dapat memaksimalkan dukungan social (20). Dukungan sosial memiliki efek positif pada hasil kesehatan melalui jalur fisik, perilaku, dan mekanisme fisiologis (21). Berbagai model dukungan sosial yang diberikan, akan tetapi bentuk dukungan infomasi dan dukungan emosional yang paling banyak ditemukan pada 6 studi yang diluas. Dukungan infomasi berupa intervensi konseling dan edukasi kepada pasien, kemudian dukungan emosional berupa pelayanan pengobatan melalui DOTS atau kunjungan rumah pasien oleh tenaga kesehatan dan juga dukungan emosional dari keluarga atau masyarakat. Kedekatan sosial antara petugas kesehatan dan pasien dapat meningkatkan pengetahuan tentang TB dan kepatuhan pengobatan dengan memberikan konseling dan pendidikan kesehatan (30). Terapi pengamatan langsung (DOT) yang mewajibkan pasien TB untuk minum obat di bawah pengamatan langsung petugas kesehatan atau anggota keluarga, merupakan kunci dari strategi DOTS yang direkomendasikan (31)

\section{Efek pada Kepatuhan pengobatan}

Dari 6 studi yang di ulas, semuanya mengkaji terkait efek dari berbagai bentuk dukungan social terhadap kepatuhan pasien dalam menjalani pengobatan TB-Resisten obat . Keenam studi tersebut menunjukkan peningkatan kepatuhan atau menekan ketidakpatuhan pengobatan pada pasien TB-resisten obat $(p=<0,05)(24,25,27-29,32)$. Hal tersebut berbanding lurus dengan penelitian yang mengungkapkan bahwa dukungan sosial berdampak positif pada 
Model dan Efek Dukungan Sosial terhadap Kepatuhan Pengobatan Pasien Tuberkulosis Resisten Obat : A Literature Review

perilaku dalam mencari bantuan kesehatan, memerangi stigmatisasi dan depresi serta meningkatkan kepatuhan pengobatan pada pasien TB (33-35).

Kesimpulan

Hasil ulasan dari literature review ini mengungkapkan bahwa berbagai model dukungan social (Dukungan informasi,emosional,finasial dan pendampingan), sangat dibutuhkan penderita TBresisten obat selama menjalani program pengobatan dalam menekan stigmatisasi, depresi atau tekanan psikologis lainnya sehingga akan meningkatkan kepatuhan pengobatan dan mencegah TB mangkir serta meningkatkan keberhasilan pengobatan . Selain itu, literature review ini menambah bukti akan pentingnya dukungan social secara komprehensif pada penderita TBresisten obat.

\section{Acknowledgment}

Penulis berterima kasih kepada semua yang telah berpartisipasi dalam penelitian ini. Penulis juga mengucapkan terima kasih kepada rekan-rekan di Fakultas Ilmu Keperawatan Universitas Hasanuddin yang telah membantu. Dan juga studi ini tidak menerima pendanaan dari pihak manapun.

\section{Conflict of Interest}

Penulis menyatakan tidak ada konflik kepentingan

\section{References}

1. World Health Organization. Global Tuberculosis Report. 2019.

2. $\quad$ Minitry of Health Indonesia. Hasil Utama Riskesdes 2018. 2018;

3. Khanal S, Elsey H, King R, Baral SC, Bhatta BR, Newell JN. Development of a patientcentred, psychosocial support intervention for multi-drug-resistant tuberculosis (MDRTB) care in Nepal. PLoS One. 2017;12(1):1-16.

4. $\quad$ Kementerian Kesehatan Republik Indonesia. situasi TB di Indonesia. In 2019.

5. Anaam MS, Mohamed Ibrahim MI, Al Serouri AW, Aldobhani A. Factors affecting patients' compliance to anti-tuberculosis treatment in Yemen. J Pharm Heal Serv Res. 2013;4(2):115-22.

6. Gebreweld FH, Kifle MM, Gebremicheal FE, Simel LL, Gezae MM, Ghebreyesus SS, et al. Factors influencing adherence to tuberculosis treatment in Asmara, Eritrea: A qualitative study. J Heal Popul Nutr. 2018;37(1):1-9.

7. Chakrabartty A, Basu P, Ali KM, Ghosh D. Tuberculosis related stigma attached to the adherence of Directly Observed Treatment Short Course (DOTS) in West Bengal, India. Indian J Tuberc. 2019;66(2):259-65.

8. Duko B, Bedaso A, Ayano G, Yohannis Z. Perceived Stigma and Associated Factors among Patient with Tuberculosis, Wolaita Sodo, Ethiopia: Cross-Sectional Study. Tuberc Res Treat. 2019;2019:1-5.

9. Skiles MP, Curtis SL, Angeles G, Mullen S, Senik T. Evaluating the impact of social support services on tuberculosis treatment default in Ukraine. PLoS One. 2018;13(8):1-13.

10. Thomas BE, Shanmugam P, Malaisamy M, Ovung S, Suresh C, Subbaraman R, et al. Psychosocio-economic issues challenging multidrug resistant tuberculosis patients: a systematic review. PLoS One. 2016;11(1):e0147397.

11. Karumbi J, Garner P. Directly observed therapy for treating tuberculosis ( Review ) SUMMARY OF FINDINGS FOR THE MAIN COMPARISON. Cochrane Database Syst Rev. 2015;(5).

12. Yan S, Zhang S, Tong Y, Yin X, Lu Z, Gong Y. Nonadherence to Antituberculosis Medications: The Impact of stigma and depressive symptoms. Am J Trop Med Hyg. 2018;98(1):262-5.

13. Naidoo P, Mwaba K. Helplessness, depression, and social support among people being treated for tuberculosis in South Africa. Soc Behav Pers. 2010;38(10):1323-34. 
14. Bojorquez I, Salazar I, Garfein RS, Cerecer P, Rodwell TC. Surveillance or support: The experience of direct observation during tuberculosis treatment. Glob Public Health. 2018;13(7):804-18.

15. Charyeva Z, Curtis S, Mullen S, Senik T, Zaliznyak O. What works best for ensuring treatment adherence. Lessons from a social support program for people treated for tuberculosis in Ukraine. PLoS One. 2019;14(8):1-13.

16. Deshmukh RD, Dhande DJ, Sachdeva KS, Sreenivas AN, Kumar AMV, Parmar M. Social support a key factor for adherence to multidrug-resistant tuberculosis treatment. Indian J Tuberc. 2018;65(1):41-7.

17. Widjanarko B, Gompelman M, Dijkers M, van der Werf MJ. Factors that influence treatment adherence of tuberculosis patients living in Java, Indonesia. Patient Prefer Adherence. 2009;3:231-8.

18. WHO. Companion handbook. World Health Organization. 2014. 464 p.

19. Wei XL, Yin J, Zou GY, Zhang ZT, Walley J, Harwell J, et al. Treatment interruption and directly observed treatment of multidrug-resistant tuberculosis patients in China. Int J Tuberc Lung Dis. 2015;19(4):413-9.

20. Li X, Wang B, Tan D, Li M, Zhang D, Tang C, et al. Effectiveness of comprehensive social support interventions among elderly patients with tuberculosis in communities in China: A community-based trial. J Epidemiol Community Health. 2018;72(5):369-75.

21. Morris MD, Moser K, Laniado-laborin R. Social, economic , and psychological impacts of MDR-TB treatment in Tijuana, Mexico : A patient' s perspective Social, economic, and psychological impacts of MDR-TB. Res Gate. 2016;17(July 2013):954-60.

22. Moher D, Liberati A, Tetzlaff J, Altman DG, Altman D, Antes G, et al. Preferred reporting items for systematic reviews and meta-analyses: The PRISMA statement. PLoS Med. 2009;6(7).

23. CASP. CASP (Randomized Controlled Trials) Checklist. 2017;

24. Yin J, Wang X, Zhou L, Wei X. The relationship between social support, treatment interruption and treatment outcome in patients with multidrug-resistant tuberculosis in China: a mixed-methods study. Trop Med Int Heal. 2018;23(6):668-77.

25. Khachadourian V, Truzyan N, Harutyunyan A, Petrosyan V, Davtyan H, Davtyan K, et al. People-centred care versus clinic-based DOT for continuation phase TB treatment in Armenia: A cluster randomized trial. BMC Pulm Med. 2020;20(1):1-10.

26. Tola HH, Shojaeizadeh D, Tol A, Garmaroudi G, Yekaninejad MS, Kebede A, et al. Psychological and educational intervention to improve tuberculosis treatment adherence in Ethiopia based on health belief model: A cluster randomized control trial. PLoS One. 2016;11(5):1-15.

27. Bhatt R, Chopra K, Vashisht R. Impact of integrated psycho-socio-economic support on treatment outcome in drug resistant tuberculosis - A retrospective cohort study. Indian $\mathrm{J}$ Tuberc. 2019;66(1):105-10.

28. Jauhar M, Widjanarko B, Java C, Support PG. Effect of Peer Group Support on the SelfEfficacy of Multi Drug Resistant Tuberculosis Patients in Underwent Compliance Treatment. Int J Heal Educ Soc. 2019;2:31-6.

29. Taneja N, Chellaiyan VG, Daral S, Adhikary M, Das TK. Home Based Care as an Approach to Improve the Efficiency of treatment for MDR Tuberculosis : A Quasi-Experimental Pilot Study. 2017;

30. Ruru Y, Matasik M, Oktavian A, Senyorita R, Mirino Y, Tarigan LH, et al. Factors associated with non-adherence during tuberculosis treatment among patients treated with DOTS strategy in Jayapura, Papua Province, Indonesia. Glob Health Action. 2018;11(1).

31. Lei X, Huang K, Liu Q, Jie YF, Tang SL. Are tuberculosis patients adherent to prescribed treatments in China? Results of a prospective cohort study. Infect Dis Poverty. 2016;5(1):1-9.

32. Baral SC, Aryal Y, Bhattrai R, King R, Newell JN. The importance of providing counselling 
and financial support to patients receiving treatment for multi-drug resistant TB: Mixed method qualitative and pilot intervention studies. BMC Public Health. 2014;14(1).

33. Lönnroth K, Glaziou P, Weil D, Floyd K, Uplekar M, Raviglione M. Beyond UHC: monitoring health and social protection coverage in the context of tuberculosis care and prevention. PLoS Med. 2014;11(9):e1001693.

34. Yan S, Zhang S, Tong Y, Yin X, Lu Z, Gong Y. Nonadherence to antituberculosis medications: the impact of stigma and depressive symptoms. Am J Trop Med Hyg. 2018;98(1):262-5.

35. Klein K, Bernachea MP, Irribarren S, Gibbons L, Chirico C, Rubinstein F. Evaluation of a social protection policy on tuberculosis treatment outcomes: A prospective cohort study. PLoS Med. 2019;16(4):e1002788. 